\title{
Article
}

\section{Fog Water Collection: Challenges beyond Technology}

\author{
Manzoor Qadir ${ }^{1, *}$, Gabriela C. Jiménez ${ }^{2}$, Rebecca L. Farnum ${ }^{3}$, Leslie L. Dodson ${ }^{4}$ and \\ Vladimir Smakhtin ${ }^{1}$ \\ 1 United Nations University Institute for Water, Environment and Health (UNU-INWEH), Hamilton, \\ ON L8P 0A1, Canada; vladimir.smakhtin@unu.edu \\ 2 Indigenous Affairs, University of Winnipeg, Winnipeg, MB R3B 2E9, Canada; gabbijimenez@gmail.com \\ 3 Department of Geography, King's College London, Strand, London WC2R 2LS, UK; \\ rebecca.farnum@kcl.ac.uk \\ $4 \quad$ Worcester Polytechnic Institute, Worcester, MA 01609, USA; lldodson@wpi.edu \\ * Correspondence: Manzoor.Qadir@unu.edu; Tel.: +1-905-667-5877
}

Received: 22 February 2018; Accepted: 20 March 2018; Published: 24 March 2018

\begin{abstract}
The Sustainable Development Goal (SDG) 6, calling for access to safe water and sanitation for all by the year 2030 supports the efforts in water-scarce countries and regions to go beyond conventional resources and tap unconventional water supplies to narrow the water demand-supply gap. Among the unconventional water resources, the potential to collect water from the air, such as fog harvesting, is by far the most under-explored. Fog water collection is a passive, low maintenance, and sustainable option that can supply fresh drinking water to communities where fog events are common. Because of the relatively simple design of fog collection systems, their operation and maintenance are minimal and the associated cost likewise; although, in certain cases, some financially constrained communities would need initial subsidies. Despite technology development and demonstrated benefits, there are certain challenges to fog harvesting, including lack of supportive policies, limited functional local institutions, inexpert communities, gender inequality, and perceived high costs without undertaking comprehensive economic analyses. By addressing such challenges, there is an opportunity to provide potable water in areas where fog intensity and duration are sufficient, and where the competition for clean water is intensifying because water resources are at a far distance or provided by expensive sources.
\end{abstract}

Keywords: water scarcity; unconventional water resources; atmospheric water; water policies and institutions; gender mainstreaming; community development; sustainable development

\section{Introduction}

Freshwater scarcity has increased over time [1,2] and is expected to further intensify [3,4], due to: uneven distribution of water resources and population densities; increasing demand for water due to population growth and mobility; changing diets; impacts of social change and economic growth on consumption preferences and lifestyles; and, changing climate and rainfall patterns [5,6]. A plethora of options are available to improve water-use efficiencies and productivity [7], but these may not be sufficient to make the conventional water resources-surface water in rivers and lakes, reservoirs, and aquifers-to meet the human needs in many water-scarce areas. Thus, water-scarce countries, regions, and communities should increasingly consider alternate, unconventional water resources in order to narrow the water demand-supply gap [8], as water scarcity forms a risk to the global economy [9] and water is increasingly considered as an instrument for international cooperation to achieve sustainable development [10].

Among the various unconventional water resources, the potential to recover water from air is by far the most under-explored. As part of the natural global water cycle, at any given time, the amount 
of water in the atmosphere is $12,900 \mathrm{~km}^{3}$, which represents $0.001 \%$ of total water and $0.04 \%$ of freshwater existing in the planet [11]. Under specific conditions, the air at ground level may contain fog, which refers to the presence of suspended liquid water droplets with diameters typically from 1 to $50 \mu \mathrm{m}$ [12]. Fog originates from the accumulation and suspension of these tiny droplets of water in the air, creating masses of humid air over land or sea. As an important source of water in desert environments, fog collection is achieved by the collision of suspended droplets on a vertical mesh, where they coalesce, after which the water runs down into a collecting drain and a tank or distribution system [13].

Gathering atmospheric moisture is far from a new idea: evidence shows that the original inhabitants of the Canary Islands dug holes under trees with large foliage to collect fog water condensing on leaves [14]. While the general concept can thus be found in indigenous heritage and practice, 20th- and 21st-century technologies have enabled fog harvesting to be considered in more systemic, mainstream water supply approaches. Modern fog interception technology was first introduced in the mid-20th century [15], and there have been major developments in fog collection systems in recent decades. One of the earliest documented experiments that was aimed at determining the volume of fog deposition was undertaken from 1901 to 1904 in South Africa, in order to investigate the feasibility and productivity of fog as a natural supplement to otherwise limited water resources [16]. The volume of fog water that was intercepted was measured with two rain gauges-one was left open in the usual manner, while a cluster of reeds was suspended above the other gauge [16]. Later studies focused on the material composition of fog collection nets and their sizes, direction, and angle of installation of fog collectors, wind intensity, and climate and topography of the area. A timeline on the history of several fog and dew water collection methods that were practiced in arid and semi-arid areas is available elsewhere [17].

While local communities continue to collect fog and dew in a multitude of ways using custom-made materials or ancient techniques, the most readily available devices are Standard Fog Collectors (SFC) and Large Fog Collectors (LFC), which are made up of polypropylene mesh nets, usually Raschel nets. One unit of the SFC has an area of $1 \mathrm{~m} \times 1 \mathrm{~m}\left(1 \mathrm{~m}^{2}\right)$, while the size of LFC varies from $40 \mathrm{~m}^{2}(4 \mathrm{~m} \times 10 \mathrm{~m})$ to $48 \mathrm{~m}^{2}(4 \mathrm{~m} \times 12 \mathrm{~m})$ per unit with the ratio of width to height for the fog collection mesh around 2.5-3.0 [18,19]. In areas where Raschel nets are too fragile to withstand heavy wind loads, other fabrics and configurations have been put in place. For example, an array of three-dimensional spacer fabric is being used as a replacement for Raschel nets that tore in the harsh environment [20]. The number, size, and type of fog collectors to be installed in a specific location depends on the fog characteristics, such as fog thickness, duration and frequency of occurrence, as well as the climate and topography of the area, water demand, and financial and human capacity of the associated community to run and maintain the fog collection system.

With different dimensions of fog water harvesting research and practice, extensive reviews are available on the history, characteristics, and technical features of fog collection [21-23]. Beyond technological developments, the information on trade-offs of policy and institutions, economics, education and capacity building, community participation, and gender equity aspects of fog water collection is scattered and fragmented. These aspects are the focus of this paper.

\section{Economics of Fog Collection}

The costs of a fog collection system are usually expressed in terms of per $\mathrm{m}^{2}$ of the mesh installed for fog collection. The cost of commonly used two-dimensional Raschel mesh fog collection systems may range from $\$ 25$ to $\$ 50$ per $\mathrm{m}^{2}$ of mesh $[19,24,25]$. For example, for a LFC with mesh size of $40 \mathrm{~m}^{2}$, the cost may range from $\$ 1000$ to $\$ 2000$, with the cost ranging between $\$ 1200$ and $\$ 2400$ for mesh size of $48 \mathrm{~m}^{2}$. However, these costs depend on the type of material (mesh), as well as piping, water tanks, and other equipment and supplies that are used in a fog collection system, and its availability and price in the area. In places where low-cost material is suitable and available for fog collection systems, the cost could be lower than the above estimations. For example, in Dar Si Hmad's Fogwater Project 
in Morocco, the cost per LFC $\left(40 \mathrm{~m}^{2}\right)$ for Raschel mesh nets was estimated at $\$ 200$ per unit [26]; i.e., $\$ 5$ per $\mathrm{m}^{2}$ of mesh, which is one-fifth of the estimated $\$ 25$ per $\mathrm{m}^{2}$ of mesh. The economics of the high-efficiency three-dimensional (3-D) spacer fabric nets are radically different as the fabric is substantially more expensive ( $\$ 830$ per $\mathrm{m}^{2}$ ) than simple Raschel nets; but, are expected to produce double or triple the amount of water collected and to resist harsh environments, such as winds around $120 \mathrm{~km} \mathrm{~h}^{-1}[27,28]$. The selection of mesh depends on its durability, price, availability, and water draining properties. In addition to material price, labor availability and associated expenses also affect the cost of establishing fog collection systems [29]. The cost of large fog collection systems would increase significantly if labor to build the systems is not volunteer or is subsidized [19,24].

Because of the relatively simple design of fog collection systems, their operation and maintenance are minimal and easy to manage, and the associated cost, likewise. Although permanent operators are not typically required due to the passive nature of the system, there would be a need for periodic maintenance and monitoring to make sure that system efficiency is preserved. The maintenance includes inspecting meshes, wires, and distribution systems, as well as repairing minor tears or ensuring that the collection system is free of any type of surface dust-accumulation or algae growth [23]. The cost of operation and maintenance depends on the local cost of labor, number of fog collectors, and specific repairs that are needed. The expected lifespan on the fog collector system ranges between 5 to 10 years for Raschel-based net systems while high-efficiency 3-D spacer fabric nets may last for more than 20 years.

While considering the cost of water collection from fog, it is important to compare it with the cost of other sources of water that are available to the communities. For example, the prices charged for water in six cities of the Atacama Desert in northern Chile in 2011 ranged from $\$ 1.96$ to $\$ 3.06$ per $\mathrm{m}^{3}$ [19]; while in Eritrea, prices fluctuate between $\$ 1.7$ and $\$ 3.3$ per $\mathrm{m}^{3}$ [24]. Because of the large variation in the material and labor costs, presence or absence of subsidies, and the efficiency of fog collection systems in different locations, there will inevitably be a wide range of costs that are associated with producing water through fog collection: $\$ 1.4$ per $\mathrm{m}^{3}$ to $\$ 16.6$ per $\mathrm{m}^{3}$ (Table 1 ).

It is important to compare the cost of producing water from fog, but equally important is the fact that such costs cannot be compared with some other sources of water, such as desalination plants, because of the differences in scale of the two technologies. Additionally, fog harvesting technologies are resource-intense during the installation phase, but then require very little maintenance or additional resources, while systems like desalination and wastewater treatment require the continuous input of energy, chemicals, and labor.

Table 1. Cost of producing a cubic meter of water from fog collection (\$ per $\mathrm{m}^{3}$ ) using Large Fog Collectors (LFC).

\begin{tabular}{cccc}
\hline Type & Cost $\left(\$ / \mathbf{m}^{3}\right)$ & Specific Information & Reference \\
\hline LFC & 16.6 & No subsidy; distribution, storage and labor costs & {$[24]$} \\
LFC & 5.7 & No subsidy; distribution, storage and labor costs & {$[19]$} \\
LFC & $2.5-3.0$ & Volunteer labor; production and distribution costs & {$[30]$} \\
LFC & $2.5-3.0$ & Volunteer labor; production and distribution costs & {$[29]$} \\
Eiffel LFC & 1.9 & Production and maintenance costs. & {$[23]$} \\
LFC & $1.4-1.6$ & Volunteer labor; production and distribution costs & {$[24]$} \\
\hline
\end{tabular}

It is important to note as well that even when water has been collected from nearby wells or cisterns without direct financial barrier, the cost has often been paid in the form of women's time, labor, and poor health. Besides satisfying water demand in water scarce areas, the value of fog collection projects is also reflected in the form of social and human capital, and by the marked reduction in the time that is spent on water collection and transportation from long distances [30]. Other indirect economic benefits are associated with relief from paying private water providers, avoiding exposure to waterborne diseases that are related to conventional storage and distribution systems, and the 
potential to use the increased water and time availability on other income-generating activities. In this way, fog harvesting systems may effectively pay for themselves over time. However, the technologies and materials generally involve a high start-up cost. In certain cases, communities will never have adequate cash flow to afford the materials and the installation of a fog water collection system. Thus, subsidies, or at least short-term loans, may well be required by low-income communities to implement fog harvesting, as it was the case in Falda Verde, Chile, where the community was highly supported by multiple stakeholders [31,32]. Ensuring that these subsidies or short-term loans are available and well targeted would be the key for fog water collection as a sustainable unconventional water source.

\section{Community Development and Gender Equity and Equality}

Although the technology of fog collection is not complex, it needs the involvement of the associated communities from early stages of the project. By engaging community members from the planning stage, throughout the installation and operation of the fog collection systems, a project team contributes to community capacity to operate the water collection system in a sustainable manner. Addressing community perspectives on fog harvesting can support the acceptance, improvement, and possible adaptation of the technology to community needs. Thus, an effective local implementing partner, such as a related government institution, a community-based organization, a non-governmental organization or a suitable combination of them, should be in place to assist the community with implementing the fog collection system and technology transfer. The local partner(s) must be committed for a period after the system is handed over to the community to provide occasional technical support when the community may need assistance that is beyond their means. Studies have demonstrated that fog collection technology works effectively at a local level when a high sense of ownership has been created by community involvement and sensitization [17].

There are examples of effective community-based fog collection systems. In a fog water collection project in Tojquia, Guatemala, there are currently 28 LFCs that are producing a daily average of over $5 \mathrm{~m}^{3}$ (5000 L) of clean water for 27 families, benefiting 127 people and their animals. The approach of providing individual LFCs for families has proven to be a sound methodology for Tojquia area [33]. There is community-based support towards maintaining LFCs at the household level [34]. Owing to community involvement, all of the original LFCs from 2006 are still operational. The water is stored in new $3 \mathrm{~m}^{3}$ water tanks on the families' own property, which is a short distance from the house. There is a waiting list of families who wish to have their own fog collector systems [33]. Contrary to this, lack of, or limited, community involvement resulted in the partial or complete failure of the fog collection systems at other places, such as Serra Malgagueta, Cape Verde; El Tofo and Padre Hurtado, Chile; and Pachamama Grande, Ecuador; among others [17]. Socio-political instability also interferes with the implementation of fog water collection systems, which can prevent external investments and discourages volunteer work $[35,36]$.

Recently, the participatory approach towards implementation of engineering projects is gaining substantial traction. While funding organizations are needed for the initial investment and continuous monitoring of activities and financial aspects, direct user's actions and commitment can help make projects sustainable over time [31]. Participatory project management can positively affect the financial, social, and human capital of the community. Family's financial capital may increase business, work and trade opportunities [29]; community's social capital may increase with the improvement of collaborative work and communal values; and human capital may be positively affected by improvements in health, education, and capacity building, either in water-related sectors or other learning opportunities. This evinces the need for strong community engagement in fog water collection projects.

Furthermore, the pursuit of gender equality and gender mainstreaming are often key to the sustainability of fog collection systems. Rosato et al. [37] reported that ensuring women's participation and capacity building led to the proper operation and maintenance of the fog collection system and its sustainability in the long-term project in the Western Highlands of Guatemala. To overcome cultural 
challenges and to support gender mainstreaming, the project team developed relationships with the community prior to the initiation of the project and incorporated women in all culturally accepted activities that are related to fog water collection and use. Women in the community had traditional roles as caregivers responsible for cooking and other domestic duties, thus the team and the male members of the community recognized and respected the importance of women's participation in the project. As they became familiar with the project, women were increasingly involved in the fog collection duties that they were comfortable with, including management activities and other decision-making actions, as they have extra time to assume new tasks. They were also happy to undertake these tasks as their contributions were recognized by the community at large.

The world's largest fog water collection and distribution system is in Southwest Morocco, in the Anti-Atlas Mountains near Sidi Ifni. Local non-profit organization Dar Si Hmad operates the system, which has involved a decade's worth of meteorological observation and partnerships with a variety of overseas researchers and engineers [20,38]. From the project's outset, women and children were identified as the key beneficiaries. In the project area, water collection is primarily the responsibility of women and girls who previously spent several hours each day collecting water from depleted and polluted wells. Thanks in large part to the involvement of community members in different phases of the project execution, along with local training about how the system and the associated processes work, and attention paid to the cultural, spiritual, and physical meanings and the experiences of fog, the increase in water availability to the community has resulted in multiple benefits [39]. Since the installation of pipes with running water directly to homes, the organization has observed improvements in public health, community stability, and increased livelihood opportunities. A key outcome has been the transformation of women's duties, with a decrease in time spent for water collection. This has enhanced the chances for women to do other tasks, for girls to remain in school, and it has increased women's participation in natural resource management and enabled the implementation of a water, sanitation, and hygiene awareness program for women and children [26]. Long-term benefits have yet to be fully evaluated, given the project's timescale, but are being monitored and are expected to produce more systemic changes in the communities. The organization and affiliated researchers are currently collecting data on demographic changes, water consumption levels, well water levels, and changes to the built environment. In 2016, the project was awarded the Momentum for Change Lighthouse Award by the United Nations Framework Convention on Climate Change (UNFCCC) at COP22 for its sustainable progress in women's empowerment and climate change adaptation [40].

When considering the social and cultural sensitivities in a community-based fog water collection system, it is important to consider several factors that may affect gender roles and responsibilities, along with other issues that are related to equity and mainstreaming, such as lifestyles and customs, education status and presence of educational institutions, poverty levels, health conditions, economic activities, and the distribution of workload for male and female segments of the community to do time-consuming and laborious water collecting tasks.

\section{Education and Capacity Building}

Although fog collection systems are based on relatively simple designs and their operation and maintenance are minimal and easy to manage, their sustainability also depends on sound professional support during the planning, financing, implementing, and regulatory stages of a project. This is important as fog collection systems are community-based, and community members are usually not fully knowledgeable of the basics or the specific operational aspects unless their capacity to manage these systems independently or with minimal support is developed [24]. As an example of effective capacity building and progressive handover, after ten years of fog collection in Tojquia in Guatemala, the community created a water committee that was elected by the community members. The committee is responsible for the operation and maintenance of the fog collectors and communication with the community and external organizations that are involved in the project [41]. This knowledge transfer 
between stakeholders is crucial, and it applies to both male and female segments of the community, as all are usually involved in fog collection and system's management. Therefore, it is appropriate to run capacity needs assessment of the local community and local institutions, followed by need-based capacity development.

Some NGOs, which are working on multiple projects around the world, accept volunteers to train local communities and institutions to implement fog water harvesting projects [42]. Given the current technological developments and access to mobile networks, it is important to highlight the role of communication technologies to support training and capacity building activities. In Dar Si Hmad's Fogwater Project in Morocco, ICT4D (information and communication technologies for development) have been used to track fog patterns and monitor the distribution system [39]. Furthermore, low-literate women were trained to use their mobile phones to send maintenance requests. These activities paved the way for literacy workshops using the phone as learning tools. The resulting infrastructure and community partnerships have had further positive impacts through the establishment of a children's water and environmental education school and an e-learning program with rural youth. Such integration increased the local functional and technological literacy rates and incorporated a scientific perspective in water management by combining community participation and engineering innovation to serve the local water needs for marginalized rural Berber populations [26].

\section{Policies and Institutions}

Despite the growing importance of fog water collection in fog-prone dry areas, its potential has not been fully explored in water scarce regions due to several governmental and institutional constraints and challenges. Among them is a lack of national water policies and action plans that consider fog water collection as a means of addressing local water shortages in water scarce areas where there is abundant fog. Where available, most national water policies and action plans do not mention atmospheric moisture harvesting on the public policy agenda. In addition to the lack of emphasis on fog collection as one policy constraint, there are institutional and human capacity challenges that are contributing to the slow uptake of the potential of fog water collection. Consequently, for the successful implementation of research-based technical interventions for fog water collection systems, there is a need to promote flexible policy frameworks with gender responsive policies, while also enhancing human and institutional capacity to maximize the benefits from fog collection in dry areas.

To achieve successful implementation of fog water harvesting projects and their sustainability in the future, it is necessary to integrate the local institutions and associated communities as stakeholders to promote their involvement and commitment. Government bodies or non-government organizations are needed to support these projects and to provide leadership to develop and operate fog water collection projects along with community participation until the community is ready to take over the control and management of the project. However, the timeframe from project inception to completion and handover to the local community depends on the project dynamics, such as the status of technology transfer and need for technical assistance, the level of local community satisfaction of the project's outcome, and the community's ability to manage the project without much external supervision. For example, the transfer of project control to the community without required management capacity could cause system malfunctions and lead to disappointment and a lack of motivation to continue with the project. Instead, local institutions can extend the time that it takes to implement and transfer a project to the local community only once the required level of skills and motivation are reached, and the adequate sustainability training and capacity are in place [30].

A major cause of underperforming or failed fog water harvesting projects is weak institutions coupled with limited inter-institutional collaboration that is reflected through largely unclear and overlapping responsibilities. This situation can be further aggravated by the lack of strong involvement and commitment by local communities in the operation and maintenance of the fog collection systems [43]. The planning and initial stages of projects are usually supported by external organizations that rely on local institutions with required expertise and involvement in the activities to ensure 
sustainability over time. Therefore, project teams should be composed of community members alongside of experts with technical and financial knowledge to support the biophysical aspects of the project, as well as professionals with social science backgrounds to address the social and cultural aspects with beneficiary communities [17].

Multiple stakeholders would benefit from fog water harvesting, while contributing to the achievement of SDG 6. Beyond local institutions, NGOs, and communities, some international NGOs and foundations-FogQuest (http:/ / www.fogquest.org/), Creating Water (http:/ / www.creatingwater. nl), Wasserstiftung (http:/ / www.wasserstiftung.de/)—are studying, testing, and implementing fog water collection systems in different parts of the world [26]. As well, some companies have been working on the mesh designs, various coatings, and other materials [29,44], and academia continue researching innovative theoretical and practical options to improve efficiency and reduce costs $[45,46]$.

\section{Conclusions and Future Perspectives}

There is an increasing number of cases using fog water collection as a community-based intervention to address local water shortages in areas where fog events are frequent. Besides a range of social, cultural, and livelihoods benefits for the associated communities through improvement in their quality of life, fog projects also have the potential to support greater gender equity, gender mainstreaming, and multi-stakeholder involvement with and between local governments, communities, NGOs, and professionals. As well, in addition to low operational and maintenance costs in providing water that meets drinking quality standards, fog water collection is an environmentally friendly intervention that does not rely on energy consumption; i.e., fog water harvesting is a green technology. Such water collection options provide ecosystem services as well [47].

As a water source, fog water collection has biophysical and socio-economic challenges. It cannot be used in all dry areas, but only in specific zones where the topographic and geographical conditions drive fog intensity and duration substantially enough to provide water to local communities. Where meteorological conditions are conducive, it can be a sustainable and cost-effective means of providing water for human and ecosystem needs. On the socio-economic front, low-income communities need initial subsidies or loans. The analyses of long-term economic benefits suggest that the start-up costs are worthwhile insofar as water is a fundamental human right and health and dignity are of incalculable importance.

Furthermore, cultural barriers and socio-political instability often restrict the participation of local communities, especially women, in decision-making processes. Lack of capacity building and planning for sustainability can directly impact on fog collection equipment life and efficiency as well as overall project implementation. These factors make it vital to include diverse local stakeholders and authorities from the beginning in order to maximize potential direct and indirect benefits (such as spin-off projects). With a comprehensive approach to overcoming these challenges, investments in a new fog water collection system can help to address community concerns. Equity aspects, other than gender equity, are also important, as these communities are typically isolated and vulnerable and an additional water source can improve their resilience.

As global efforts to achieve sustainable development advance, fog water collection has the potential to contribute to water-related efforts to achieve SDG 6 targets in water-scarce areas by the year 2030. The wider application and scope of fog water collection systems may go beyond the SDG 6 to apply to other sustainable goals. For example, in urban areas, smog (a mixture of smoke and fog in the air) is emerging as a significant air quality challenge, impacting respiratory systems and overall human and animal health, and threatening human lives by increasing the chance of vehicle accidents due to low visibility [48]. Smog interception using fog collectors may be utilized to decrease air pollution in smog-prone areas. This would offer smog collection as complementary to the use of cleaner-burning fuels in industrial, residential, and commercial sectors, and fuel-efficient vehicles. In this way, fog collection systems would also contribute to SDG 3.9 to reduce the number of deaths and illnesses from air pollution and contamination; and, SDG 11, which focuses on making cities 
and human settlements safe, resilient, and sustainable. In addition, implementation of fog collection systems can contribute to SDG 5 addressing gender equality and empower all women and girls.

The needed paradigm shift from an attitude that considers water scarcity as a permanent and chronic challenge in remote water-scarce areas, to one that looks beyond conventional water supplies, is an outstanding backdrop in which to address the problem of local water scarcity. Thus, this is the time to explore and harness the full potential of fog water collection in water-scarce countries with frequent fog events in specific areas. This can be triggered by (1) revisiting national water management action plans and assessing the value that fog water collection brings; (2) undertaking situation analysis to achieve the maximum potential of fog water collection vis-à-vis associated economic, societal, social, environmental, and health trade-offs; (3) updating national water policies and budgets, water pricing, and subsidies options, and cost recovery mechanisms to include fog collection systems; (4) building capacity in local water institutions and communities to support community based implementation of fog collection systems; (5) facilitating associated communities by implementing participatory actions and projects, and considering social and cultural sensitivities, gender roles and responsibilities, lifestyles and customs, education status, poverty levels, and economic activities; (6) establishing a base of fog harvesting knowledge and best practices, identifying and testing innovations, and showcasing functional examples to inform policy makers for supportive actions and investment decisions; and, (7) undertaking public awareness activities to encourage uptake of fog collection systems in areas with potential for fog water collection.

Acknowledgments: This work is part of the UNU-INWEH's project on unconventional water resources. UNU-INWEH is supported by the Government of Canada through Global Affairs Canada.

Author Contributions: This paper was jointly developed and written by all authors. M.Q. coordinated this process.

Conflicts of Interest: The authors declare no conflict of interest.

\section{References}

1. Rijsberman, F.R. Water scarcity: Fact or fiction? Agric. Water Manag. 2006, 80, 5-22. [CrossRef]

2. Djuma, H.; Bruggeman, A.; Eliades, M.; Lange, M.A. Non-conventional water resources research in semi-arid countries of the Middle East. Desalination Water Treat. 2016, 57, 2290-2303. [CrossRef]

3. Mekonnen, M.M.; Hoekstra, A. Four billion people facing severe water scarcity. Sci. Adv. 2016, 2, e1500323. [CrossRef] [PubMed]

4. Damania, R.; Desbureaux, S.; Hyland, M.; Islam, A.; Moore, S.; Rodella, A.; Russ, J.; Zaveri, E. Uncharted Waters: The New Economics of Water Scarcity and Variability; The World Bank Group: Washington, DC, USA, 2017.

5. Falkenmark, M.; Lundqvist, J.; Widstrand, C. Macro-scale water scarcity requires micro-scale approaches. Nat. Resour. Forum 1989, 13, 258-267. [CrossRef] [PubMed]

6. White, C. Understanding water scarcity: Definitions and measurements. In Global Water: Issues and Insights; Grafton, R.Q., Wyrwoll, P., White, C., Allendes, D., Eds.; ANU Press: Canberra, Australia, 2014; pp. 161-165, ISBN 9781925021677.

7. Unver, O.; Bhaduri, A.; Hoogeveen, J. Water-use efficiency and productivity improvements towards a sustainable pathway for meeting future water demand. Water Secur. 2007, 1, 21-27. [CrossRef]

8. World Bank. Beyond Scarcity: Water Security in the Middle East and North Africa; Overview Booklet; World Bank: Washington, DC, USA, 2017.

9. Hoekstra, A.Y.; Chapagain, A.K.; van Oel, P.R. Advancing Water Footprint Assessment Research: Challenges in Monitoring Progress towards Sustainable Development Goal 6. Water 2017, 9, 438. [CrossRef]

10. Farnum, R. Drops of Diplomacy: Questioning the Scale of Hydro-Diplomacy through Fog-Harvesting. J. Hydrol. 2017, in press.

11. The Water Cycle. Available online: https://earthobservatory.nasa.gov/Features/Water/ (accessed on 12 February 2018).

12. Ritter, A.; Regalado, C.M.; Guerra, J.C. Quantification of Fog Water Collection in Three Locations of Tenerife (Canary Islands). Water 2015, 7, 3306-3319. [CrossRef] 
13. Abdul-Wahab, S.A.; Lea, V. Reviewing fog water collection worldwide and in Oman. Int. J. Environ. Stud. 2008, 65, 487-500. [CrossRef]

14. Marzol, M.V. La Captación del Agua de la Niebla en la Isla de Tenerife; Servicio de Publicaciones de la Caja General de Ahorros de Canarias: Las Palmas de Gran Canaria, Spain, 2005.

15. Gioda, E.; Espejo, R.; Acosta Baladón, A. Fog collectors in tropical areas. In Proceedings of the Symposium on Precipitation and Evaporation, Bratislava, Slovakia, 20-24 September 1993; pp. 273-278.

16. Olivier, J. Fog-water harvesting along the West Coast of South Africa: A feasibility study. Water SA 2002, 28, 349-360. [CrossRef]

17. Fessehaye, M.; Abdul-Wahab, S.A.; Savage, M.J.; Kohler, T.; Gherezghiher, T.; Hurni, H. Fog-water collection for community use. Renew. Sustain. Energy Rev. 2014, 29, 52-62. [CrossRef]

18. Schemenauer, R.S.; Cereceda, P. A proposed standard fog collector for use in high-elevation regions. J. Appl. Meteorol. 1994, 33, 1313-1322. [CrossRef]

19. LeBoeuf, R.; de la Jara, E. Quantitative goals for large-scale fog collection projects as a sustainable freshwater resource in northern Chile. Water Int. 2014, 39, 431-450. [CrossRef]

20. Trautwein, P.; Frost, E.; Jutzi, S.; Hruschka, H. Natural Wells in the Sky; Wasserstiftung: Schäftlarn, Germany, 2016.

21. Maliva, R.; Missimer, T. Rainwater, Stormwater, and Fog Harvesting. In Arid Lands Water Evaluation and Management; Environmental Science and Engineering (Environmental Engineering); Springer: Berlin, Heidelberg, 2012; pp. 529-558.

22. Pérez-Díaz, J.L.; Ivanov, O.; Peshev, Z.; Álvarez-Valenzuela, M.A.; Valiente-Blanco, I.; Evgenieva, T.; Dreischuh, T.; Gueorguiev, O.; Todorov, P.V.; Vaseashta, A. Fogs: Physical Basis, Characteristic Properties, and Impacts on the Environment and Human Health. Water 2017, 9, 807. [CrossRef]

23. Domen, J.K.; Stringfellow, W.T.; Camarillo, M.K.; Gulati, S. Fog water as an alternative and sustainable water resource. Clean Technol. Environ. Policy 2014, 16, 235-249. [CrossRef]

24. Fessehaye, M.; Abdul-Wahab, S.A.; Savage, M.J.; Kohler, T.; Gherezghiher, T.; Hurni, H. Assessment of fog-water collection on the eastern escarpment of Eritrea. Water Int. 2017, 42, 1022-1036. [CrossRef]

25. Holmes, R.; Rivera, J.D.; de la Jara, E. Large fog collectors: New strategies for collection efficiency and structural response to wind pressure. Atmos. Res. 2014, 151, 236-249. [CrossRef]

26. Dodson, L.L.; Bargach, J. Harvesting Fresh Water from Fog in Rural Morocco: Research and Impact Dar Si Hmad's Fogwater Project in Aït Baamrane. Procedia Eng. 2015, 107, 186-193. [CrossRef]

27. Obtaining drinking water from fog. Available online: https://www.aqualonis.com/cloudfisher (accessed on 12 February 2018).

28. Trautwein, P. Gaining drinking water with fog collectors CloudFisher Pro ${ }^{\mathrm{TM}}$ and CloudFisher mini ${ }^{\mathrm{TM}}$. In Proceedings of the 7th International Conference on Fog, Fog Collection and Dew, Wroclaw, Poland, 19-24 July 2016.

29. Batisha, A. Feasibility and sustainability of fog harvesting. Sustain. Water Qual. Ecol. 2015, 6, 1-10. [CrossRef]

30. Klemm, O.; Schemenauer, R.S.; Lummerich, A.; Cereceda, P.; Marzol, V.; Corell, D.; Fessehaye, G.M. Fog as a Fresh-Water Resource: Overview and Perspectives. AMBIO 2012, 41, 221-234. [CrossRef] [PubMed]

31. Correggiari, M.; Castelli, G.; Bresci, E.; Salbitano, F. Fog Collection and Participatory Approach for Water Management and Local Development: Practical Reflections from Case Studies in the Atacama Drylands. In Water and Land Security in Drylands; Ouessar, M., Gabriels, D., Tsunekawa, A., Evett, S., Eds.; Springer: Cham, Switzerland, 2017; pp. 141-158.

32. Carter, V.; Schemenauer, R.S.; Osses, P.; Streeter, H. The Atacama Desert Fog Collection Project at Falda Verde, Chile. In Proceedings of the 4th International Conference on Fog, Fog Collection and Dew, La Serena, Chile, 22-27 July 2007.

33. Guatemala - Tojquia 2006 - Ongoing. Fog Collection Operational Project. Available online: http:/ / www fogquest.org/project-information/current-projects/tojquia/ (accessed on 12 February 2018).

34. Schemenauer, R.S.; Rosato, M.; Carter, V. Fog Collection Projects in Tojquia and La Ventosa, Guatemala. In Proceedings of the 4th International Conference on Fog, Fog Collection and Dew, La Serena, Chile, 22-27 July 2007.

35. Haiti-Salagnac Plateau 2001-2002. Fog Collection Evaluation Project. Available online: http://www. fogquest.org/project-information/projects/haiti-salagnac-plateau/ (accessed on 12 February 2018).

36. FogQuest-Past Projects. Available online: http://www.fogquest.org/project-information/projects/ (accessed on 12 February 2018). 
37. Rosato, M.; Rojas, F.; Schemenauer, R.S. Not just beneficiaries: Fostering participation and local management capacity in the Tojquia fog-collection project, Guatemala. In Proceedings of the 5th International Conference on Fog, Fog Collection and Dew, Münster, Germany, 25-30 July 2010; pp. 248-251.

38. A Ground-breaking Project: Harvesting Water from Fog. Available online: http://darsihmad.org/fog/ (accessed on 12 February 2018).

39. Dodson, L.L. A foggy desert: Equitable Information Flow for a Fogwater System in Southwest Morocco. Ph.D. Thesis, ATLAS Institute, University of Colorado Boulder, Boulder, CO, USA, 2014.

40. Winners of 2016 UNFCCC Momentum for Change Award Announced. Available online: http:/ / newsroom. unfccc.int/climate-action/2016-momentum-for-change-lighthouse-activities / (accessed on 12 February 2018).

41. Schemenauer, R.S.; Zanetta, N.; Rosato, M.; Carter, V. The Tojquia, Guatemala Fog Collection Project 2006 to 2016. In Proceedings of the 7th International Conference on Fog, Fog Collection and Dew, Wroclaw, Poland, 24-19 July 2016.

42. Become a Fog Farmer. Available online: http://www.creatingwater.nl/built-your-own (accessed on 12 February 2018).

43. Schemenauer, R.S.; Bignell, B.; Makepeace, T. Fog Collection Projects in Nepal: 1997 to 2016. In Proceedings of the 7th International Conference on Fog, Fog Collection and Dew, Wroclaw, Poland, 24-19 July 2016.

44. Rajaram, M.; Heng, X.; Oza, M.; Luo, C. Enhancement of fog-collection efficiency of a Raschel mesh using surface coatings and local geometric changes. Colloids Surfaces A Physicochem. Eng. Asp. 2016, 508, $218-229$. [CrossRef]

45. Regalado, C.M.; Ritter, A. The design of an optimal fog water collector: A theoretical analysis. Atmos. Res. 2016, 178-179, 45-54. [CrossRef]

46. Tuure, J.; Korpela, A.; Hautala, M.; Hakojärvi, M.; Mikkola, H.; Alakukku, L. Development of Cost-Efficient Dew and Fog Collectors for Water Management in Semiarid and Arid Regions of Developing Countries. In Proceedings of the 7th International Conference on Fog, Fog Collection and Dew, Wroclaw, Poland, 19-24 July 2016.

47. Vanham, D. Does the water footprint concept provide relevant information to address the water-food-energy -ecosystem nexus? Ecosyst. Serv. 2016, 17, 298-307. [CrossRef]

48. Zhou, L.; Dai, Y. How Smog Awareness Influences Public Acceptance of Congestion Charge Policies. Sustainability 2017, 9, 1579. [CrossRef]

(C) 2018 by the authors. Licensee MDPI, Basel, Switzerland. This article is an open access article distributed under the terms and conditions of the Creative Commons Attribution (CC BY) license (http://creativecommons.org/licenses/by/4.0/). 